\title{
Kiwifruit fibre level influences the predicted production and absorption of SCFA in the hindgut of growing pigs using a combined in vivo-in vitro digestion methodology
}

\author{
Carlos A. Montoya*, Shane M. Rutherfurd and Paul J. Moughan \\ Riddet Institute, Massey Institute of Food Science and Technology, Massey University, Palmerston North, New Zealand \\ (Submitted 9 April 2015 - Final revision received 25 May 2015 - Accepted 25 June 2015 - First published online 17 August 2015)
}

\begin{abstract}
Combined in vivo (ileal cannulated pig) and in vitro (faecal inoculum-based fermentation) digestion methodologies were used to predict the production and absorption of SCFA in the hindgut of growing pigs. Ileal and faecal samples were collected from animals $(n 7)$ fed diets containing either 25 or $50 \mathrm{~g} / \mathrm{kg}$ DM of kiwifruit fibre from added kiwifruit for $14 \mathrm{~d}$. Ileal and faecal SCFA concentrations normalised for food DM intake (DMI) and nutrient digestibility were determined. Ileal digesta were collected and fermented for $38 \mathrm{~h}$ using a fresh pig faecal inoculum to predict SCFA production. The predicted hindgut SCFA production along with the determined ileal and faecal SCFA were then used to predict SCFA absorption in the hindgut and total tract organic matter digestibility. The determined ileal and faecal SCFA concentrations (e.g. 8.5 and $4.4 \mathrm{mmol} / \mathrm{kg}$ DMI, respectively, for acetic acid for the low-fibre diet) represented only $0 \cdot 2-3 \cdot 2 \%$ of the predicted hindgut SCFA production (e.g. $270 \mathrm{mmol} / \mathrm{kg}$ DMI for acetic acid). Predicted production and absorption of acetic, butyric and propionic acids were the highest for the high-fibre diet $(P<0.05)$, but these inter-diet differences were not observed for the ileal and faecal SCFA concentrations $(P>0.05)$. In conclusion, determined ileal and faecal SCFA concentrations represent only a small fraction of total SCFA production, and may therefore be misleading in relation to the effect of diets on SCFA production and absorption. Considerable quantities of SCFA are produced and absorbed in the hindgut of the pig by the fermentation of kiwifruit.
\end{abstract}

Key words: In vivo digestion: In vitro fermentation: SCFA: Absorption: Growing pigs: Kiwifruit dietary fibre

Food not only undergoes digestion by the mammalian gastrointestinal tract (GIT) digestive enzymes but can also be subjected to fermentation by the resident microbial population, and both dietary and endogenous (derived from the body) organic materials can be fermented ${ }^{(1-3)}$. The degree of fermentation depends on the diet and the region of the GIT, with greater fermentation occurring in the hindgut compared with the small intestine $^{(2,4)}$. The main end products of microbial fermentation in the GIT are the SCFA. SCFA have been associated with a number of beneficial effects in the GIT, including intestinal tissue proliferation, enhanced absorption of minerals and water, modulation of GIT contractility, increased numbers of beneficial bacteria and reduced numbers of pathogenic bacteria. In addition, SCFA are the main energy source for epithelial cells ${ }^{(1,5-8)}$. Given the importance of SCFA, information about their production and absorption in the hindgut is a key consideration.

A number of studies in both humans and farm animals have determined SCFA concentrations in different regions of the GIT and also in the faeces, and these have been used to draw conclusions regarding the production of SCFA in the hindgut ${ }^{(2,9,10)}$. The latter approach has limitations, however, as
SCFA concentrations are not a measure of SCFA production but rather are the net result of SCFA production and absorption $^{(11-13)}$. Seemingly, only approximately $5 \%$ of the SCFA produced in the hindgut are excreted in the faeces ${ }^{(7,13)}$. The appearance of SCFA in the portal vein and in exhaled breath have also been used ${ }^{(13-16)}$ as measures related to production. However, these methods do not account for the utilisation of SCFA within the intestinal epithelium (portal blood method) or the body in general (exhaled breath). Another approach is to collect ileal digesta for a given diet and use this as a substrate for in vitro fermentation with a faecal inoculum (to simulate the action of the microbes in the hindgut ${ }^{(17-21)}$ in order to obtain an estimate of SCFA production based on the amount of DM entering the large intestine and the measure of fermentability. The latter approach has been used to estimate the available energy content of selected foods for humans ${ }^{(21)}$. Several groups have also used this approach to estimate the SCFA production in the hindgut ${ }^{(17,18,22,23)}$, but very few studies $^{(18,22)}$ have determined SCFA absorption.

The overall aim of this study was to use a combined in vivoin vitro digestion methodology ${ }^{(17,18,21,22)}$ to predict both the

\footnotetext{
Abbreviations: DMI, DM intake; GIT, gastrointestinal tract; OM, organic matter.
} 
hindgut production and the absorption of SCFA in growing pigs (an animal model for the digestion of food in humans) fed diets containing kiwifruit as the only source of dietary fibre. Kiwifruit was selected as it is a well-characterised source of dietary fibre for humans, containing pectins, hemicelluloses and cellulose $^{(24)}$. In contrast to previous studies ${ }^{(18,22)}$, the hindgut absorption of SCFA also includes the SCFA present in terminal ileal digesta, thereby taking into account the SCFA entering the hindgut as a result of fermentation in the small intestine.

\section{Methods}

\section{Dietary treatments}

Two diets containing 133 and $266 \mathrm{~g}$ of green kiwifruit (Actinidia deliciosa $\mathrm{cv}$. Hayward) DM/kg diet DM, as the only dietary fibre source ( 25 or $50 \mathrm{~g}$ fibre/kg DM, respectively), were formulated to meet the nutrient requirements of growing pig as prescribed by the National Research Council ${ }^{(25)}$ (Table 1). The diet concentrations of kiwifruit fibre were chosen to provide concentrations of total dietary fibre similar to those reported for a typical Western diet $(30-70 \mathrm{~g} / \mathrm{kg} \mathrm{DM})^{(26)}$. The daily ration was calculated as $90 \mathrm{~g}$ of $\mathrm{DM} / \mathrm{kg}$ of metabolic body weight $\left(\mathrm{BW}^{0.75}\right)$ per $\mathrm{d}$ and was fed to the pigs as two equal meals provided at 09.00 and 16.00 hours. Titanium dioxide was included as an indigestible marker in the diets. Kiwifruit were added to the semi-synthetic experimental diets and were freshly peeled and crushed just before each meal. Fresh water was provided ad libitum.

Table 1. Ingredients and determined nutrient compositions of the experimental diets

\begin{tabular}{|c|c|c|}
\hline & \multicolumn{2}{|c|}{ Diet fibre concentration $(\mathrm{g} / \mathrm{kg})$} \\
\hline & 25 & 50 \\
\hline \multicolumn{3}{|l|}{ Ingredient ( $\mathrm{g} / \mathrm{kg})$} \\
\hline Kiwifruit $\mathrm{DM}^{\star}$ & 133 & 266 \\
\hline Casein & 157 & 148 \\
\hline Soyabean oil & 50 & 50 \\
\hline Sucrose & 70 & - \\
\hline Sodium chloride & 3 & 3 \\
\hline Vitamin/mineral premix $†$ & 5 & 3 \\
\hline Calcium carbonate & 1 & 1 \\
\hline Dicalcium phosphate & 19 & 18 \\
\hline Wheat starch & 559 & 506 \\
\hline Titanium dioxide & 3 & 3 \\
\hline \multicolumn{3}{|l|}{ Nutrient (g/kg DM) } \\
\hline Crude protein & 171 & 162 \\
\hline Total lipid & 57 & 61 \\
\hline Ash & 33 & 40 \\
\hline Soluble dietary fibre & 7 & 13 \\
\hline Insoluble dietary fibre & 21 & 35 \\
\hline Total dietary fibre & 28 & 48 \\
\hline Gross energy (MJ/kg DM) & 18.5 & $18 \cdot 8$ \\
\hline
\end{tabular}

\section{In vivo assay}

Animals and housing. Ethics approval for the animal trial was obtained from the Animal Ethics Committee, Massey University. A total of fourteen entire male pigs (PIC Camborough $46 \times$ PICboar 356L) (41.4 (sD 2.98) kg mean body weight) were housed individually in pens $(1.5 \times 1.5 \mathrm{~m})$ in a room maintained at $21(\mathrm{sD} 2)^{\circ} \mathrm{C}$ with a $10 \mathrm{~h}$ light-14 h dark cycle. Pigs were surgically modified by the implantation of a simple $\mathrm{T}$ cannula at the terminal ileum as previously described ${ }^{(27)}$.

Experimental design. Pigs were randomly allocated to the two kiwifruit-containing diets (seven pigs/diet), which were fed to the animals for $16 \mathrm{~d}$. Faecal samples were collected directly on the 14 th and 15 thd following anal stimulation, and were immediately frozen at $-20^{\circ} \mathrm{C}$ for determining total tract digestibility of organic matter (OM) and at $-80^{\circ} \mathrm{C}$ for determining faecal SCFA concentrations. Ileal digesta were collected into a plastic bag attached to the cannula. Digesta were collected from each pig on the 15th and 16th day and over a 6-h period each day starting from $1 \mathrm{~h}$ after feeding. Plastic bags were changed every $30 \mathrm{~min}$ and the digesta were frozen immediately to minimise further digestion. From the first batch of fresh digesta, a subsample was collected into a sealed Eppendorf tube for SCFA determination in order to reduce the risk of volatilisation. The ileal digesta samples were used to determine the apparent ileal digestibility of OM, ileal SCFA concentrations and also to provide a substrate for the in vitro fermentation assay. The faecal samples were collected before collecting the ileal digesta samples in order to avoid interference with the hindgut flow of DM.

\section{In vitro fermentation assay}

Fermentation of the ileal digesta was carried out using a pig faecal inoculum as previously described ${ }^{(20,21)}$. Fresh faeces samples were collected from five healthy pigs (fed a commercial grower diet) into isolated containers flushed with $\mathrm{CO}_{2}$ at $37^{\circ} \mathrm{C}$. In brief, the pig faecal inoculum was prepared by homogenising the faeces with $0 \cdot 1 \mathrm{~m}$-phosphate buffer at $\mathrm{pH} 7$ $(1: 5, \mathrm{w} / \mathrm{v})$ and filtering the homogenate. Inoculum $(5 \mathrm{ml})$ was added to a McCartney bottle containing $5 \mathrm{ml}$ phosphate buffer either alone (blank incubation) or containing $100 \mathrm{mg}$ of finely ground freeze-dried ileal digesta sample collected from the pigs fed the experimental diet. There were four replicate bottles per blank or ileal digesta sample; one bottle was used to determine the SCFA after fermentation and the other three bottles were used to determine the OM fermentability. All the bottles were flushed with $\mathrm{CO}_{2}$, capped and incubated with the pig inoculum for $38 \mathrm{~h}$ at $37^{\circ} \mathrm{C}$. After incubation, the SCFA concentrations in the material of one of the replicate bottles were determined after thoroughly mixing the contents of the bottle and transferring an aliquot $(1 \mathrm{ml})$ to an Eppendorf tube, which was then centrifuged at $14000 \mathrm{rpm}$ for $15 \mathrm{~min}$ at $4^{\circ} \mathrm{C}$. The supernatant $(500 \mu \mathrm{l})$ was transferred to another Eppendorf tube and frozen at $-20^{\circ} \mathrm{C}$ before analysis for SCFA. The other three bottles were placed in an autoclave $\left(121^{\circ} \mathrm{C}\right.$ for $20 \mathrm{~min}$ ) to completely inactivate the bacteria and to remove the end products of $\mathrm{OM}$ 
fermentation (e.g. SCFA). The DM of the unfermented residue was determined in the remaining three bottles by drying them in an oven at $60^{\circ} \mathrm{C}$ until they reached a constant weight

\section{Chemical analysis}

The diets, ileal digesta and faeces were analysed in duplicate for $\mathrm{DM}, \mathrm{OM}$, ash and titanium dioxide. DM, OM and ash were determined using standard procedures ${ }^{(28)}$, and titanium dioxide was determined following the method of Short et al. ${ }^{(29)}$. The diets were also analysed for crude protein, gross energy, diethyl ether extract ${ }^{(28)}$ and soluble, insoluble and total dietary fibre contents ${ }^{(30)}$. The dried contents of the in vitro fermentation media from the three bottles were analysed for OM.

SCFA were determined in the faecal and ileal digesta samples and in the supernatants obtained from the in vitro fermentation. Thawed faecal samples were prepared for analysis by mixing them with Milli-Q-water (Millipore) $\left(4^{\circ} \mathrm{C}\right)(1: 3, \mathrm{w} / \mathrm{v})$. Thawed ileal digesta and the prepared faecal samples were then centrifuged at $14000 \mathrm{~g}$ for $15 \mathrm{~min}$ at $4^{\circ} \mathrm{C}$. The supernatants were collected and analysed in duplicate for acetic, butyric, propionic and valeric acids, using a Shimadzu GC2010 Gas Chromatograph System fitted with a Zebron ZB-FFAP column $(30 \mathrm{~m}$ $\times 0.32 \mathrm{~mm}$ ) (Phenomenex) as described previously ${ }^{(31)}$.

\section{Calculations and statistical analysis}

In vivo assay. The apparent ileal and faecal digestibilities and the hindgut fermentability were calculated as follows:

Apparent digestibility $(\%)=\left(1-\left(\left(\mathrm{OM}_{\mathrm{F} / \mathrm{I}} / \mathrm{OM}_{\mathrm{D}}\right) \times\left(\mathrm{T}_{\mathrm{D}} / \mathrm{T}_{\mathrm{F} / \mathrm{I}}\right)\right)\right)$

$$
\times 100
$$

Hindgut fermentability invivo $(\%)=\left(1-\left(\left(\mathrm{OM}_{\mathrm{F}} / \mathrm{OM}_{\mathrm{I}}\right) \times\left(\mathrm{T}_{\mathrm{I}} / \mathrm{T}_{\mathrm{F}}\right)\right)\right)$

$$
\times 100
$$

where $T_{D}$ and $T_{F / I}$ are the titanium dioxide contents $(\mathrm{g} / \mathrm{kg} \mathrm{DM})$ in the diet and in the faeces or ileal digesta, respectively; $\mathrm{OM}_{\mathrm{D}}$ and $\mathrm{OM}_{\mathrm{F} / \mathrm{I}}$ are the contents of $\mathrm{OM}(\mathrm{g} / \mathrm{kg} \mathrm{DM})$ in the diet and in the faeces or ileal digesta, respectively.

The concentrations of SCFA in the terminal ileal digesta and in the faeces (normalised for the food DM intake (DMI)) were calculated using the following equation:

Normalised SCFA concentration ( $\mathrm{mmol} / \mathrm{kg} \mathrm{DMI})$

$$
=\operatorname{SCFA} \text { concentration }(\mathrm{mmol} / \mathrm{kg} \mathrm{DM}) \times\left(\mathrm{T}_{\mathrm{D}} / \mathrm{T}_{\mathrm{F} / \mathrm{I}}\right) \text {. }
$$

In vitro fermentation assay. Predicted hindgut fermentability of OM and SCFA produced by fermentation were obtained after in vitro fermentation of the ileal digesta with the faecal inoculum and calculated using the following equations:

$$
\begin{aligned}
& \text { Hindgut fermentability } \text { invitro }(\%)=\left(\mathrm{OM}_{\mathrm{b}}-\left(\mathrm{OM}_{\mathrm{a}}\right.\right. \\
& \left.\left.-\left(\left(\mathrm{OM}_{\text {blank initial }}+\mathrm{OM}_{\text {blank final }}\right) / 2\right)\right)\right) / \mathrm{OM}_{\mathrm{b}} \times 100,
\end{aligned}
$$

SCFA produced by fermentation ( $\mathrm{mmol} / \mathrm{kg}$ DM incubated)

$$
\begin{aligned}
= & \left(\mathrm{SCFA}_{\text {sample }}-\left(\left(\mathrm{SCFA}_{\text {blank initial }}+\mathrm{SCFA}_{\text {blank final }}\right) / 2\right)\right) / \\
& \text { sample weight }(\mathrm{g} \mathrm{DM}) \times 1000,
\end{aligned}
$$

where $\mathrm{OM}_{\mathrm{b}}$ and $\mathrm{OM}_{\mathrm{a}}$ are the $\mathrm{OM}$ (mg) of the ileal digesta either before or after in vitro fermentation. $\mathrm{OM}_{\text {blank initial, }} \mathrm{OM}_{\text {blank final }}$, SCFA $_{\text {blank initial }}$ and SCFA blank final are the OM (mg) and the SCFA $(\mathrm{mmol})$ in the blank bottle (which contained inoculum but no ileal digesta) before (initial) and after (final) in vitro fermentation, respectively ${ }^{(20)}$.

Predicted total tract digestibility, SCFA production and absorption in the hindgut. The predicted apparent total tract digestibility $\left(\mathrm{PAD}_{\text {faecal }}\right)$ of $\mathrm{OM}$ and the SCFA production and absorption in the hindgut were calculated based on combining results for in vivo ileal digesta flows (ileal cannulated pig) with in vitro concentrations (hindgut fermentation). The in vivo values represented digestion in the upper gut, and the in vitro data represented fermentation in the hindgut. $\mathrm{PAD}_{\text {faecal }}$ of $\mathrm{OM}$ and predicted hindgut SCFA production were calculated as follows:

$$
\begin{aligned}
& \mathrm{PAD}_{\text {faecal }}(\%)=\left(\mathrm{OM}_{D}-(((100-\text { Hindgut OM fermentability } \text { invitro }) /\right. \\
& \text { 100) } \times \text { ileal OM flow)) } / \mathrm{OM}_{\mathrm{D}} \times 100, \\
& \text { Predicted hindgut SCFA production ( } \mathrm{mmol} / \mathrm{kg} \mathrm{DMI}) \\
& =\text { SCFA produced by fermentation } \\
& \text { ( } \mathrm{mmol} / \mathrm{kg} \text { ileal digesta DM incubated) } \\
& \times \text { ileal DM flow }(\mathrm{kg} \mathrm{DM} / \mathrm{kg} \text { DMI }) \text {, }
\end{aligned}
$$

where $\mathrm{OM}_{\mathrm{D}}(\mathrm{g} / \mathrm{kg} \mathrm{DM})$ is the OM content in the diet, and ileal OM flow ( $\mathrm{g} / \mathrm{kg}$ DMI) is the ileal flow of OM. Hindgut OM

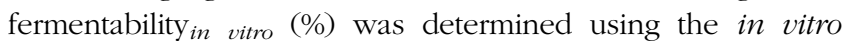
fermentation assay.

The amounts of SCFA entering the hindgut (i.e. ileal normalised SCFA concentration) and the amounts produced in the hindgut (i.e. in vitro predicted hindgut SCFA production) were used to predict the amounts of SCFA absorbed in the hindgut based on the following equation:

$$
\begin{aligned}
\text { Amount of SCFA absorbed from hindgut }(\mathrm{mmol} / \mathrm{kg} \mathrm{DMI}) \\
=\text { in vitro predicted hindgut } \\
\quad \text { SCFA production }(\mathrm{mmol} / \mathrm{kg} \mathrm{DMI}) \\
\quad+\text { ileal SCFA concentration }(\mathrm{mmol} / \mathrm{kg} \mathrm{DMI}) \\
\quad \text { - faecal SCFA concentration }(\mathrm{mmol} / \mathrm{kg} \mathrm{DMI}),
\end{aligned}
$$

Extent of SCFA absorbed in the hindgut (\%)

$$
\begin{aligned}
= & (\text { amount of SCFA absorbed from the hindgut } \\
& (\mathrm{mmol} / \mathrm{kg} \mathrm{DM} \text { intake }) /(\text { in vitro predicted } \\
& \text { hindgut SCFA production }(\mathrm{mmol} / \mathrm{kg} \mathrm{DMI}) \\
& + \text { ileal SCFA concentration }(\mathrm{mmol} / \mathrm{kg} \mathrm{DMI})) \times 100 .
\end{aligned}
$$

Statistical analyses were performed using SAS (version 9.3, 2011; SAS Institute Inc.). A two-independent samples $t$ test procedure was performed to test the effect of dietary kiwifruit fibre (25 and $50 \mathrm{~g} / \mathrm{kg} \mathrm{DM}$ ) on both the in vivo and in vitro data. 
The same procedure was used to compare the determined and predicted digestibilities and fermentabilities for each kiwifruit diet. A paired $t$ test procedure was used to compare the ileal and faecal SCFA concentrations. The normal distribution for the $t$ test was evaluated using the ODS graphics procedure of SAS. When the variances were unequal, the $P$ value reported was obtained using the Satterthwaite separate variance $t$ test.

\section{Results}

The diet containing the highest concentration of kiwifruit fibre had a 1.7 -fold greater content of total dietary fibre than the lower-fibre diet (Table 1). This difference, however, was reduced to only $1 \cdot 2$-fold in the ileal digesta $(345$ and $399 \mathrm{~g} / \mathrm{kg}$ DM ileal digesta for pigs fed diets containing 25 and $50 \mathrm{~g}$ fibre/kg DM, respectively).

\section{Determined ileal and faecal concentrations of SCFA} (in vivo)

There was no difference $(P>0.05)$ for either the ileal or the faecal concentrations of the SCFA between the two fibrecontaining diets (Table 2). Similarly, there was no difference between the ileal and faecal SCFA concentrations within each diet $(P>0.05)$, with the exception of acetic acid for the diet containing $50 \mathrm{~g} / \mathrm{kg}$ of fibre. For this diet, the ileal concentration of acetic acid was 2.54 -fold higher than the faecal concentration $(P<0 \cdot 05)$.

\section{Production of SCFA after in vitro fermentation and} predicted hindgut SCFA production (in vivo-in vitro)

The SCFA produced by in vitro fermentation were similar for all the SCFA between the two fibre-containing diets $(P>0.05$; Table 3). In contrast, the predicted hindgut production of acetic, butyric and propionic acids was higher $(P<0.05)$ for the diet containing $50 \mathrm{~g} / \mathrm{kg}$ of fibre compared with the diet containing $25 \mathrm{~g} / \mathrm{kg}$ of fibre (1.7-, 1.9- and 1.5-fold higher, respectively; Table 3$)$. There was no difference $(P>0.05)$ between diets in the case of valeric acid.

\section{Predicted hindgut SCFA absorption (in vivo-in vitro)}

The predicted amounts of acetic, butyric and propionic acids absorbed from the hindgut were higher for the diet containing the highest fibre concentration (1.8-, 1.9- and 1.5-fold higher, respectively) $(P<0.05$; Table 3$)$. There was no difference $(P>0.05)$ between diets for valeric acid. The predicted apparent absorption of the SCFA in the hindgut was similar between the two fibre-containing diets $(P<0.05$; Table 3$)$, and near complete.

\section{Determined (in vivo) and predicted (in vivo-in vitro) digestibilities}

There was an effect of dietary fibre concentration on the determined apparent ileal and total tract digestibilities $(P<0 \cdot 05$; Table 4). The diet containing the highest concentration of fibre had a lower determined digestibility of OM $(3 \cdot 1 \%$ unit

Table 2. Ileal and faecal concentrations of SCFA for ileal cannulated pigs fed diets containing different concentrations of fibre (Mean values with their pooled standard errors; $n 7$ per group)

\begin{tabular}{|c|c|c|c|c|}
\hline & \multicolumn{2}{|c|}{ Diet fibre concentration ( $\mathrm{g} / \mathrm{kg} \mathrm{DM}$ ) } & \multirow[b]{2}{*}{ SEM } & \multirow[b]{2}{*}{$P$} \\
\hline & 25 & 50 & & \\
\hline \multicolumn{5}{|c|}{ Determined ileal SCFA concentrations (mmol/kg DM intake) (in vivo) ${ }^{*}$} \\
\hline Acetic & 8.51 & $14 \cdot 68$ & 3.120 & 0.097 \\
\hline Butyric & 1.09 & $1 \cdot 11$ & 0.428 & 0.956 \\
\hline Propionic & 2.07 & 2.40 & 0.943 & 0.730 \\
\hline Valeric & 0.08 & 0.17 & 0.063 & 0.195 \\
\hline \multicolumn{5}{|c|}{ Determined faecal SCFA concentrations ( $\mathrm{mmol} / \mathrm{kg} \mathrm{DM}$ intake) (in vivo) $\dagger$} \\
\hline Acetic & 4.35 & 5.77 & 1.735 & 0.431 \\
\hline Butyric & 0.58 & 0.79 & 0.370 & 0.586 \\
\hline Propionic & 0.83 & 1.36 & 0.590 & 0.392 \\
\hline Valeric & 0.21 & 0.29 & 0.127 & 0.545 \\
\hline \multicolumn{5}{|c|}{ Statistical analysis for ileal $v$. faecal SCFA concentrations } \\
\hline \multicolumn{5}{|l|}{ Acetic } \\
\hline$P$ & 0.061 & 0.015 & & \\
\hline SEM & 1.809 & 2.652 & & \\
\hline \multicolumn{5}{|l|}{ Butyric } \\
\hline$P$ & 0.535 & 0.346 & & \\
\hline SEM & 0.742 & 0.738 & & \\
\hline \multicolumn{5}{|l|}{ Propionic } \\
\hline$P$ & 0.981 & 0.729 & & \\
\hline SEM & 0.617 & 0.359 & & \\
\hline \multicolumn{5}{|l|}{ Valeric } \\
\hline$P$ & 0.112 & 0.109 & & \\
\hline SEM & 0.166 & 0.089 & & \\
\hline
\end{tabular}

* The ileal concentrations of SCFA were determined directly from the frozen samples of ileal digesta collected from the pigs.

† Faecal concentrations were determined directly from the frozen samples of faeces collected from the pigs. 
Table 5. Determined and predicted hindgut fermentability of organic matter for ileal cannulated pigs fed diets containing different concentrations of fibre

(Mean values with their pooled standard errors; $n 7$ per group)

\begin{tabular}{|c|c|c|c|c|}
\hline & \multicolumn{2}{|c|}{ Diet fibre concentration (g/kg DM) } & \multirow[b]{2}{*}{ SEM } & \multirow[b]{2}{*}{$P$} \\
\hline & 25 & 50 & & \\
\hline Determined hindgut fermentability (\%) (in vivo) ${ }^{*}$ & $48 \cdot 4$ & $47 \cdot 3+$ & $4 \cdot 68$ & 0.808 \\
\hline Predicted hindgut fermentability (\%) (in vivo-in vitro methodology) $\ddagger$ & 39.2 & 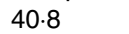 & 2.23 & 0.485 \\
\hline \multicolumn{5}{|l|}{ Statistical analysis for determined $v$. predicted hindgut fermentability } \\
\hline$P$ & 0.024 & 0.126 & & \\
\hline SEM & 3.28 & 3.89 & & \\
\hline
\end{tabular}

* In vivo hindgut fermentability was determined in pigs as the difference between the ileal and faecal flows of organic matter. $\dagger n 6$, an outlier was removed from the statistical analysis.

$\ddagger$ In vitro hindgut fermentability in pigs was determined after in vitro fermentation of the ileal digesta with a pig faecal inoculum.

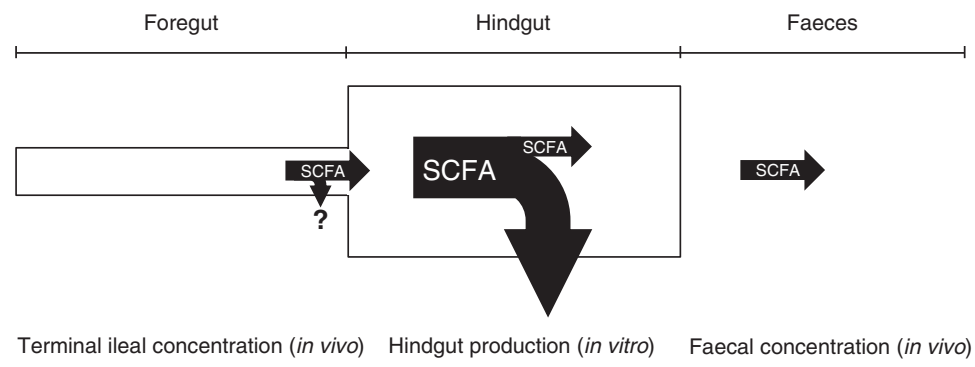

Fig. 1. Principle of the combined in vivo-in vitro methodology to determine the hindgut production and absorption of SCFA. The '?' represents the SCFA absorbed in the small intestine, which were not determined in this study.

\section{Discussion}

\section{Predicted production and absorption of SCFA in the} hindgut

Owing to the difficulty in investigating the production and absorption of SCFA in the GIT directly, studies investigating SCFA production in humans and farm animals focus mainly on the faecal concentrations of SCFA ${ }^{(10,32)}$. The latter approach, however, has limitations because faecal SCFA concentrations reflect the overall net production and absorption of SCFA in the GIT, but provide no information about the production or the absorption of SCFA per se $e^{(11-13)}$. Other studies have been carried out to determine SCFA absorption by quantifying the appearance of SCFA in portal blood and in exhaled breath ${ }^{(13-16)}$. However, significant amounts of SCFA absorbed from the GIT are utilised by the epithelial cells, and therefore may not appear in the bloodstream ${ }^{(1,7,33)}$; thus, the latter approaches are also limited. In the present study, a combined in vivo-in vitro methodology was used to predict the production and absorption of SCFA in the hindgut using diets containing different concentrations of kiwifruit as a model dietary fibre. The latter approach used the growing pig as a model to derive estimates of upper tract digestion and an in vitro fermentation assay, where pig ileal digesta were incubated with a pig faecal inoculum, to model hindgut fermentation. By combining the two (in vivo and in vitro) sets of data, the production and absorption of SCFA in the hindgut can be predicted ${ }^{(22)}$. In contrast to previous studies, the predicted amount of SCFA absorbed from the hindgut also considered the SCFA entering the hindgut (based on determined ileal concentrations) (Fig. 1). The latter explains the higher values of SCFA absorbed than that produced in the hindgut. It is important to note that the present combined in vivo-in vitro approach does not account for the SCFA produced and absorbed in the upper GIT (?' in Fig. 1), but the contribution of the stomach and small intestine to SCFA production and absorption across the entire GIT is expected to be relatively low. In addition, this approach does not consider the SCFA potentially produced by the fermentation of endogenous material entering the large intestine directly from colonic tissues.

The similar content of total dietary fibre in the ileal digesta of both kiwifruit fibre diets explains the similar hindgut SCFA concentrations after in vitro fermentation. The predicted production of total SCFA in the hindgut of pigs fed diets containing 25 and $50 \mathrm{~g} / \mathrm{kg}$ DM of kiwifruit fibre was 472 and $777 \mathrm{mmol} / \mathrm{kg}$ DMI, respectively. Christensen et al. ${ }^{(22)}$ also, using a combined in vivo-in vitro approach, reported similar predicted production of total SCFA in the hindgut of ileal cannulated pigs to the values reported in our study with wheat flour, wheat bran and oat bran as fibre sources (369-850 mmol/kg DMI). The wider range in the predicted hindgut production of SCFA in the study of Christensen et al. ${ }^{(22)}$ may be explained by a higher and wider range in dietary fibre content of the diets $(63-110 \mathrm{~g} / \mathrm{kg}$ DM of dietary fibre) and the type of fibre used.

In the present study, the normalised faecal concentrations of SCFA represented only $0 \cdot 5-1 \cdot 6 \%$ of the predicted hindgut SCFA production when examined across both fibre-containing diets 
and all SCFA. Such low values are not surprising, as faecal SCFA output is the net result of SCFA production and absorption in the hindgut, and therefore is a measure of the unabsorbed SCFA rather than SCFA production per se.

It is noteworthy that based on faecal SCFA concentrations it can be concluded that dietary fibre concentration had no effect on SCFA production and absorption. However, based on the combined in vivo-in vitro approach, it is apparent, perhaps not unexpectedly, that higher dietary fibre concentrations led to a greater production of SCFA in the simulated hindgut fermentation. Clearly, using faecal SCFA concentrations to describe SCFA production can be misleading, and the present study supports the findings of McNeil et al. ${ }^{(11)}$, Cummings \& Macfarlane $^{(12)}$ and Topping \& Clifton ${ }^{(13)}$, all of whom have cautioned against the use of faecal SCFA flows and concentrations for describing SCFA production in the hindgut.

Dietary fibre comprises a mixture of complex NSP (e.g. hemicellulose and cellulose), lignin, resistant starch, oligosaccharides and resistant maltodextrins that differ among foods ${ }^{(34)}$. The relative amounts of SCFA produced by fermentation are influenced by the type of dietary fibre being fermented $^{(5,12,35)}$, and it is not appropriate to extrapolate the results of the present study to other fibre sources. However, using the approach described in the present study, it is possible to predict the production and absorption of SCFA in the hindgut of pigs after consumption of fibre sources other than kiwifruit and such studies are warranted. This approach can also be applied to humans by collecting ileal digesta from the growing pig (an accepted animal model for upper gut digestion in humans), which can be fermented in vitro with a human faecal inoculum $^{(20,21)}$. The combined in vivo-in vitro methodology can also be extended to other species of animals (e.g. poultry).

The predicted extent of SCFA absorption in the hindgut, based on the amounts of SCFA entering the hindgut (estimated from the SCFA in the ileal digesta) and the SCFA produced in the hindgut, was high (mean absorption across all SCFA and dietary treatments was $99.8 \%$ ) as has been reported previously $(95-99 \%)^{(7,13)}$. Based on the SCFA content of the ileal digesta, it would appear that as much as $3 \%$ of the SCFA absorbed from the hindgut was derived from fermentation in the small intestine. Given that it is likely that a high proportion of the SCFA produced in the small intestine was also absorbed in the small intestine, it would appear that microbial fermentation in the small intestine may be more quantitatively significant than is often recognised. Indeed, a recent study has shown that the corrected upper gut fermentation of the soluble fraction of kiwifruit fibre was $80 \%{ }^{(27)}$.

\section{Predicted total tract digestibility and hindgut fermentability}

When the fibre-containing diets were compared, both the predicted and determined hindgut fermentabilities of OM showed the same trend in results (i.e. no difference in hindgut fermentability between the two fibre-containing diets). Similarly, both the predicted and determined values for total tract digestibility of OM led to the same conclusions (i.e. the diet containing the lowest fibre concentration had higher total tract digestibility). In addition, and in general, the predicted and determined total tract digestibilities of OM were very similar quantitatively, supporting the combined in vivo-in vitro approach $^{(21)}$. Although in the present study the combined in vivo-in vitro method was used to predict the total tract digestibility of $\mathrm{OM}$, this technique can also be used to predict the digestibility of other compounds (e.g. NSP) ${ }^{(18,22)}$.

In conclusion, the combined in vivo-in vitro methodology is a useful approach for predicting the production and absorption of SCFA in the hindgut. The ileal and faecal concentrations of SCFA per se do not reflect the SCFA production and absorption in the hindgut and may lead to misleading conclusions. Considerable quantities of SCFA are produced and absorbed in the hindgut when pigs are fed diets enriched with kiwifruit.

\section{Acknowledgements}

The authors acknowledge Stuart Saigeman and Trent D. Olson for running the animal trials and ZESPRI International Ltd for supplying the kiwifruit.

This study was funded by ZESPRI International Ltd. ZESPRI International Ltd had no role in the design, analysis or writing of this manuscript.

C. A. M., S. M. R. and P. J. M. were responsible for planning the study. C. A. M. was responsible for conducting the experiments. In addition, C. A. M. carried out the statistical analysis and prepared the first draft of the manuscript that was revised by S. M. R. and P. J. M. All the authors read and approved the final version of the manuscript.

There are no conflicts of interest to declare.

\section{References}

1. Bergman EN (1990) Energy contributions of volatile fatty acids from the gastrointestinal tract in various species. Physiol Rev 70, $567-590$.

2. Højberg O, Canibe N, Knudsen B, et al. (2003) Potential rates of fermentation in digesta from the gastrointestinal tract of pigs: effect of feeding fermented liquid feed. Appl Environ Microbiol 69, 408-418.

3. Nakamura N, Lin HC, McSweeney CS, et al. (2010) Mechanisms of microbial hydrogen disposal in the human colon and implications for health and disease. Annu Rev Food Sci Technol 1, 363-395.

4. Jensen BB \& Jørgensen H (1994) Effect of dietary fiber on microbial activity and microbial gas production in various regions of the gastrointestinal tract of pigs. Appl Environ Microbiol 60, 1897-1904.

5. Henningsson A, Björck I \& Nyman M (2001) Short-chain fatty acid formation at fermentation of indigestible carbohydrates. Scand J Nutr 45, 165-168.

6. Williams BA, Verstegen MWA \& Tamminga S (2001) Fermentation in the large intestine of single-stomached animals and its relationship to animal health. Nutr Res Rev 14, 207-227.

7. Roy CC, Kien CL, Bouthillier L, et al. (2006) Short-chain fatty acids: ready for prime time? Nutr Clin Pract 21, 351-366.

8. Vinolo MAR, Rodrigues HG, Nachbar RT, et al. (2001) Regulation of inflammation by short chain fatty acids. Nutrients 3, 858-876. 
9. Weaver GA, Tangel CT, Krause JA, et al. (1997) Acarbose enhances human colonic butyrate production. J Nutr 127, $717-723$.

10. Whelan K, Judd PA, Preedy VR, et al. (2005) Fructooligosaccharides and fiber partially prevent the alterations in fecal microbiota and short-chain fatty acid concentrations caused by standard enteral formula in healthy humans. J Nutr $\mathbf{1 3 5}$, 1896-1902.

11. McNeil NI, Cummings JH \& James WPT (1978) Short chain fatty-acid absorption by human large intestine. Gut 19, 819-822.

12. Cummings JH \& Macfarlane GT (1991) The control and consequences of bacterial fermentation in the human colon. J Appl Bacteriol 70, 443-459.

13. Topping DL \& Clifton PM (2001) Short-chain fatty acids and human colonic function: roles of resistant starch and nonstarch polysaccharides. Physiol Rev 81, 1031-1064.

14. Giusi-Perier A, Fiszlewicz M \& Rerat A (1989) Influence of diet composition on intestinal volatile fatty acid and nutrient absorption in unanaesthetized pigs. J Anim Sci 67, 386-402.

15. Muir JG, Lu ZX, Young GP, et al. (1995) Resistant starch in the diet increases breath hydrogen and serum acetate in human subjects. Am J Clin Nutr 61, 792-799.

16. Regmi PR, van Kempen TATG, Matte JJ, et al. (2011) Starch with high amylose and low in vitro digestibility increases short-chain fatty acid absorption, reduces peak insulin secretion, and modulates incretin secretion in pigs. J Nutr 141, 398-405.

17. McBurney MI \& Sauer WC (1993) Fiber and large bowel energy absorption: validation of the integrated ileostomyfermentation model using pigs. J Nutr 123, 721-727.

18. Anguita M, Canibe N, Perez JF, et al. (2006) Influence of the amount of dietary fiber on the available energy from hindgut fermentation in growing pigs: use of cannulated pigs and in vitro fermentation. J Anim Sci 84, 2766-2778.

19. Coles LT, Moughan PJ \& Darragh AJ (2005) In vitro digestion and fermentation methods, including gas production techniques, as applied to nutritive evaluation of foods in the hindgut of humans and other simple-stomached animals. Anim Feed Sci Technol 123-124, 421-444.

20. Coles LT, Moughan PJ, Awati A, et al. (2013) Optimisation of inoculum concentration and incubation duration for an in vitro hindgut dry matter digestibility assay. Food Chem $\mathbf{1 3 6}$, 624-631.

21. Coles LT, Moughan PJ, Awati A, et al. (2013) Validation of a dual in vivo-in vitro assay for predicting the digestibility of nutrients in humans. J Sci Food Agric 93, 2637-2645.
22. Christensen DN, Bach Knudsen KE, Wolstrup J, et al. (1999) Integration of ileum cannulated pigs and in vitro fermentation to quantify the effect of diet composition on the amount of short-chain fatty acids available from fermentation in the large intestine. J Sci Food Agric 79, 755-762.

23. Wang JF, Zhu YH, Li DF, et al. (2004) In vitro fermentation of various fiber and starch sources by pig fecal inocula. J Anim Sci 82, 2615-2622.

24. Redgwell RJ, Melton LD \& Brasch DJ (1991) Changes to pectic and hemicellulose polysaccharides of kiwifruit ripening. Acta Hortic 297, 627-634.

25. National Research Council (1998) Nutrient Requirements of Swine, 10th revised ed. Washington, DC: National Academies Press.

26. Baer DJ, Rumpler WV, Miles CW, et al. (1997) Dietary fibre decreases the metabolisable energy content and nutrient digestibility of mixed diets fed to humans. J Nutr 127, 579-586.

27. Montoya CA, Rutherfurd SM \& Moughan PJ (2015) Non-dietary gut materials interfere with the determination of dietary fiber digestibility in growing pigs when using the Prosky method. J Nutr 145, 1966-1972.

28. Association of Official Analytical Chemists (2007) Official Methods of Analysis, 18th ed. Arlington, VA: Association of Official Analytical Chemists.

29. Short FJ, Gorton P, Wiseman J, et al. (1996) Determination of titanium dioxide added as an inert marker in chicken digestibility studies. Anim Feed Sci Technol 59, 215-221.

30. Prosky L, Asp NG, Schweizer TF, et al. (1988) Determination of insoluble, soluble, and total dietary fibre in foods and food products: interlaboratory study. J Assoc Off Anal Chem 71, 1017-1023.

31. Bindelle J, Pieper R, Montoya CA, et al. (2011) Nonstarch polysaccharide-degrading enzymes alter the microbial community and the fermentation patterns of barley cultivars and wheat products in an in vitro model of the porcine gastrointestinal tract. FEMS Microbiol Ecol 76, 553-563.

32. Fredstrom SB, Lampe JW, Jung HJ, et al. (1994) Apparent fiber digestibility and fecal short-chain fatty acid concentrations with ingestion of two types of dietary fiber. J Parenter Enteral Nutr 18, 14-19.

33. Von Engelhardt W, Rönnau K., Rechkemmer G, et al. (1989) Absorption of short-chain fatty acids and their role in the hindgut of monogastric animals. Anim Feed Sci Technol 23, 45-53.

34. Jones J (2014) CODEX-aligned dietary fiber definitions help to bridge the 'fiber gap'. Nutr J 13, 13-34.

35. Macfarlane S \& Macfarlane GT (2003) Regulation of shortchain fatty acid production. Proc Nutr Soc 62, 62-72. 